\title{
Development of Region-Specific Antisera and Immunoassay for Human Prostate-Specific Antigen (PSA) with Use of Purposely Designed Synthetic Peptides
}

\author{
Masanobu Aoxi ${ }^{1}$, Shingo NAgaSaWA ${ }^{2}$, Ikuo Katoh ${ }^{2}$, Noboru Yanalhara ${ }^{2}$, Toshihiko Iwanaga ${ }^{3}$ and Kimio Funita ${ }^{1}$ \\ ${ }^{1}$ Department of Urology, Hamamatsu University School of Medicine, 1-20-1 Handayama, Hamamatu 431-3192, ${ }^{2}$ Yanaihara Institute, Inc., \\ 2480-1 Awakura, Fujinomya 418-0011, ${ }^{3}$ Laboratory of Anatomy, Graduate School of Veterinary Medicine, Hokkaido University, Kita- \\ 18 Nishi-9, Kita-ku, Sapporo 060-0818, Japan
}

(Received 20 November 2002; and accepted 29 November 2002)

\begin{abstract}
Prostate-specific antigen (PSA) immunoassay is now widely used in the clinical management of prostate cancer. However, the diversity of molecular forms of the protein caused the results of PSA immunoassay variable depending on specificity of the antibody used. The current study provided an efficient method for production of anti-PSA antisera strictly specific for the expected region of the molecule using purposely designed synthetic peptides. The synthetic peptides included PSA $\left(42^{-92}\right),(53-92),(50-70),(76-92),(174-184)$ and $(199-210)$. Immunization of the peptides in rabbits afforded seventeen kinds of antisera. Binding activity to native PSA and immunohistochemistry with human prostate proved nine of them, three anti-PSA (42-92), two anti-PSA (53-92) and four anti-PSA $(50-70)$ antisera, to be useful for further experiment. None of antisera against PSA (76-92) and (174-184) showed binding activity with native PSA and immunostaining in human prostate. Using anti-PSA (53-92) antisera with synthetic PSA (42-92) peptide as antigen and biotinyl-Gly-Gly-PSA (42-92) as labeled antigen, a novel type of PSA specific enzyme immunoassay system was successfully developed. The assay system is well defined in terms of region specificity, which is highly advantageous for its clinical use. In addition, the strict region-specificity will make the assay system useful as an analytical tool for characterization of the PSA molecule in blood. Attempts for production of PSA antisera specific to other regions of PSA molecule along this line is now in progress.
\end{abstract}

Correspondence to: Dr. M. Aoki at above address

Tel: +81-53-435-2306, Fax: +81-53-435-2305

Email: masa@hama-med.ac.jp

Abbreviations:

Fmoc: 9-fluorenylmethoxycarbonyl

OBut: $t$-butyl ester

PEG: polyethyleneglycol

Pbf: 2, 2, 4, 6, 7-pentamethyldihydrobenzofuran-5-sulfonyl

Trt: trityl

But: $t$-butyl

Boc: $t$-butyloxycarbonyl

HATU: 0-(7-azabenzotriazol-1-yl) 1, 1, 3, 3,-tetramethyluronium hexafluorophosphate

EDT: 1, 2-ethanedithiol

TIPS: triisopropylsilane
Prostate-specific antigen (PSA) is a single chain glycoprotein consisting of 237 amino acid residnes and the molecular mass was estimated to be $28.5^{-} 34$ $\mathrm{kDa}$ depending on the methods used $(19,20)$. PSA has chymotrypsin-like substrate specificity belonging to the serine protease family (18). The protein is one of the three members of the kallikrein family with the tissue kallikrein $(\mathrm{hK} 1)$ and the glandular kallikrein (hK2) $(15,18)$.

Serum PSA is now widely used in the clinical management of prostate cancer and it is recognized as the most useful tumor maker for screening and monitoring of patients with prostate cancer. However, important problems still remain to be solved in 
immunological measurement of PSA. In fact, it is not uncommon that different commercial PSA immunoassays gave different results in the same patient, which claims the need of standardization of PSA immunoassays $(3,9,19)$

PSA is known to exist in various molecular forms in blood. Those include free forms, intact and clipped, and complexed forms with other proteins such as $\alpha_{1}$-antichymotrypsin and $\alpha_{2}$-macroglobulin (18). This is supposed to make the values of PSA in blood measured by immunoassay variable depending on specificity and crossreactivity of the antibody used. In this context, standardization of antibody specificity used in PSA assay may provide a clue to solve the problem. It is, however, entirely by chance to obtain the antibody against a certain protein having the desired specificity, i.e. epitope.

The current study aimed at production on purpose of strictly region-specific anti-PSA antisera with use of purposely designed synthetic peptides. In addition, using the anti-synthetic peptide antisera and synthetic peptide antigen and labeled antigen, PSAspecific enzyme immunoassay (EIA) system was developed for clinical measurement of serum PSA.

\section{MATERIALS AND METHODS}

Peptide Synthesis. PSA-related peptides were synthesized by a continuous flow solid phase methodology with Fmoc-strategy using an automated peptide synthesizer (A-pplied Biosystems model 9050 plus or Pioneer, Applied Biosystems, Foster, USA). The peptides currently prepared include PSA (42-92), $(53-92),\left(50^{-70}\right),\left(76^{-92}\right),(174-184)$ and $\left(199^{-}\right.$ 210) (Fig. 1). As an example, the synthesis of PSA $(42-92)$ is described below.

The peptide chain was elongated on a Fmoc-Asp $\left(\mathrm{OBu}^{t}\right)$-PEG-resin (0.1 mmol, 100-200 mesh, Applied Biosystems) with use of Fmoc derivatives of amino acids such as $\operatorname{Arg}(\mathrm{Pbf})$, His (Trt), Ser $\left(\mathrm{Bu}^{\prime}\right)$, Leu, Phe, Pro, Glu $\left(\mathrm{OBu}^{t}\right)$, Asp $\left(\mathrm{OBu}^{t}\right)$, Thr $\left(\mathrm{Bu}^{t}\right)$, Gly, Gin (Trt), Val, Tyr (Bu'), Met, Lys (Boc), Asn
(Trt) and Cys (Trt) (Peptide Institute Inc., Osaka, Japan). The Fmoc-amino acids (4-fold excess amount each) were successively introduced to the resin according to the peptide sequence using HATU as coupling reagent. Introduction of Fmoc-Arg (Pbf) corresponding to position 53 yielded the protected peptide-resin $(2.02 \mathrm{~g})$, a part of which $(0.50 \mathrm{~g})$ was taken out for preparation of PSA (53-92). After construction of the desired sequence (42-92), the protected peptide-resin $(0.70 \mathrm{~g})$ was treated with TFA $(18.9 \mathrm{~mL})$ in the presence of $\mathrm{H}_{2} \mathrm{O}(0.50 \mathrm{~mL})$, EDT $(0.50 \mathrm{~mL})$ and TIPS $(0.20 \mathrm{~mL})$ for $120 \mathrm{~min}$ at room temperature to yield crude preparation of peptide $(270 \mathrm{mg})$. The crude peptide $(270 \mathrm{mg})$ was purified by reverse phase HPLC on a column of Develosil ODS-HG-5 $(20 \times 250 \mathrm{~mm}$, Nomura Chemical Co., Seto, Japan) with a solvent system of $0.01 \mathrm{~N}$ $\mathrm{HCl} / \mathrm{CH}_{3} \mathrm{CN}(82 / 18 \rightarrow 66 / 34, \mathrm{v} / \mathrm{v} \%)$ over $30 \mathrm{~min}$ at a flow rate of $10 \mathrm{~mL} / \mathrm{min}$ to yield the desired product (49.0 mg).

Biotinyl-Gly-Gly-PSA (42-92) was synthesized, according to the same manner as described above, using the protected PSA (42-92)-PEG-resin $(0.30$ g). After construction of the desired protected peptide-resin $(0.30 \mathrm{~g})$, deprotection was carried out with TFA $(4.73 \mathrm{~mL})$ containing $\mathrm{H}_{2} \mathrm{O}(0.13 \mathrm{~mL})$, EDT $(0.13 \mathrm{~mL})$ and TIPS $(0.05 \mathrm{~mL})$ for $120 \mathrm{~min}$ at room temperature. The crude peptide $(120 \mathrm{mg})$ was purified by HPLC on a column of Develosil ODSHG-5 $(20 \times 250 \mathrm{~mm})$ with a solvent system of $0.01 \mathrm{~N} \mathrm{HCl} / \mathrm{CH}_{3} \mathrm{~N}(78 / 22 \rightarrow 67 / 33, \mathrm{v} / \mathrm{v} \%)$ over $30 \mathrm{~min}$ at a flow rate of $10 \mathrm{~mL} / \mathrm{min}$ to yield the desired product $(14.0 \mathrm{mg})$.

The other five peptides mentioned above and their biotinyl-Gly-Gly-derivatives were synthesized in the same manner. PSA (199-210) was constructed on Fmoc-Arg (Pbf)-PEG-resin, so that the product was PSA (199-210)-R. High purity of each peptide was confirmed by analytical HPLC and MALDI-TOF mass analysis.

Production of Anti-Synthetic Peptide Antisera. Prepa-

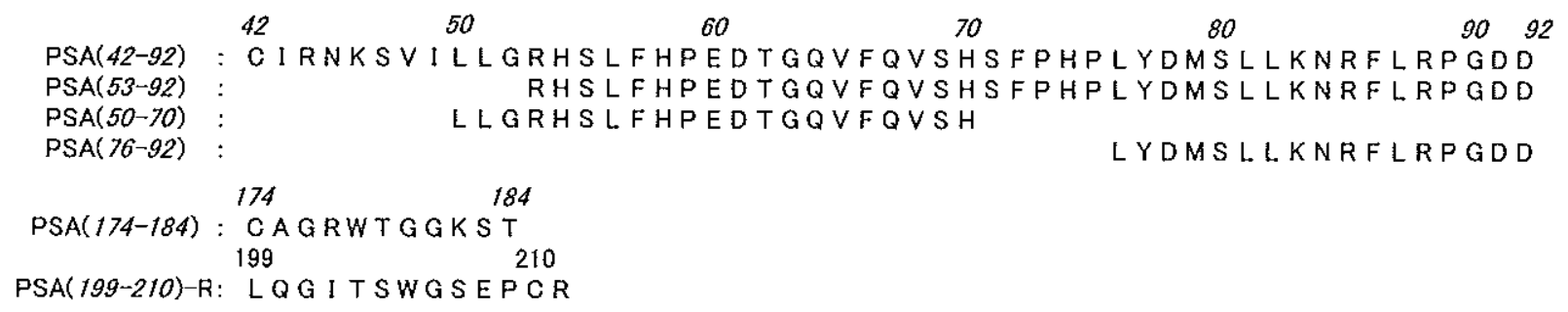

Fig. 1 Amino acid sequences of human PSA-related synthetic peptides. 
ration of synthetic peptide-protein conjugates as immunogen: Sulfosuccinimidyl 4-(N-maleimidomethyl)- cyclohexane-1-carboxylate (15.4 mg) (Pi-erce, Rockford, IL, USA) was added to a solution of synthetic PSA (42-92) (10.5 mg) and keyhole limpet hemocyanin (KLH) (30 mg) (Pierce) in 0.1 M PBS, pH $7.4(3.5 \mathrm{~mL})$. The mixture was kept for $4 \mathrm{~h}$ at room temperature and passed through a Sephadex G50 column for desalting to yield the conjugate. The other five kinds of synthetic peptides were also conjugated with $\mathrm{KLH}$, respectively, in the same manner using dimethyl suberimide $\cdot 2 \mathrm{HCl}$ (Pierce) as cross-linking reagent. Some of peptide antigens were used in carrier free form (Table 1).

Immunization. Each of the conjugates $(2.0 \mathrm{mg})$ or peptides $(1.0 \mathrm{mg})$ dissolved in saline $(0.5 \mathrm{~mL})$ was added to $50 \%(\mathrm{v} / \mathrm{v})$ polyvinylpyrorridon (M. W. $25,000-30,000$, Merck, Darmstadt, Germany) in saline $(0.5 \mathrm{~mL})$ and the mixture was emulsified with Freund's complete adjuvant (Calbiochem, La Jolla, CA, USA) $(1.1 \mathrm{~mL})$ for $15 \mathrm{~min}$ in an ice bath. The emulsion was injected intradermally into seventeen rabbits (New Zealand white, male, 2.1-2.5 kg). Additional immunization was carried out at two-week intervals using a half dose of the immunogen used for the primary one. After the third immunization, rabbits were bled from the marginal ear vein 10 days after each immunizations.

Table 1 Antigen peptides and antisera produced against the peptides.

\begin{tabular}{lcc}
\hline immunogen & carrier protein & anrisenum number \\
\hline PSA (42-92) & KLH & $\begin{array}{c}\text { RY1187, RY1188, } \\
\text { RY1189 }\end{array}$ \\
PSA (53-92) & none & $\begin{array}{c}\text { RY756, RY757 } \\
\text { PSA (50-70) }\end{array}$ \\
none & RY610, RY611 \\
PSA (50-70) & KLH & RY612, RY613 \\
PSA (76-92) & KLH & RY636, RY637 \\
PSA (174-184) & KLH & RY638, RY639 \\
PSA (199-210)-R & none & RY614, RY615 \\
PSA (199-210)-R & KLH & RY621, RY622 \\
\hline
\end{tabular}

R: Arg
Determination of antiserum titer: A solution (0.1 $\mathrm{mL}$ ) of native PSA preparation (Cortex Biochem, San Leandro, CA, USA) in $0.1 \mathrm{M} \mathrm{NaHCO}_{3}$ (1 $\mu \mathrm{g} / \mathrm{mL}$ ) was added to each well of a microtiter plate (NUNC, Maxisorp, Roskilde, Denmark) and the plate was kept for $18 \mathrm{~h}$ at room temperature. The solution was decantated and $25 \%$ diluted BlockAce (Dainihon Pharmaceutical, Osaka, Japan) was added to the wells $(0.3 \mathrm{~mL} /$ well $)$. The plate was kept for $48 \mathrm{~h}$ at $4^{\circ} \mathrm{C}$ and the wells were washed three times with washing solution comprising $0.05 \%$ Tween 20 in saline. Properly diluted antiserum was added to the wells $(0.1 \mathrm{~mL} / \mathrm{well})$ and the plate was kept for $18 \mathrm{~h}$ at $4^{\circ} \mathrm{C}$. The wells were washed three times with washing solution and horseradish peroxidase (HRP)conjugated anti-rabbit IgG (ICN, Aurora, Ohio, USA) solution (1:5,000 diluted with Dulbecco's PBS(-) containing $0.05 \%$ Tween 20 and $0.1 \%$ bovine serum albumin) was added $(0.1 \mathrm{~mL} / \mathrm{well})$. The plate was kept for $1.5 \mathrm{~h}$ at room temperature and the wells were washed four times with washing solution. A solution of $o$-phenylene diamine (OPD, Sigma, St Louis, Mo, USA) in 0.1 M citrate-phosphate buffer containing $0.05 \%$ hydrogen peroxide (1 $\mathrm{mg} / \mathrm{mL})$ was added $(0.1 \mathrm{~mL} / \mathrm{wvell})$. The plate was kept for $0.5 \mathrm{~h}$ at room temperature and then $2 \mathrm{~N}$ $\mathrm{H}_{2} \mathrm{SO}_{4}$ was added $(0.1 \mathrm{~mL} /$ well). Optical absorption of each well was measured at $492 \mathrm{~nm}$ by a microtiter plate reader Multiskan MS (Dainihon Pharmaceutical).

Immunohistochemistry. Fresh human prostate was obtained in a prostatectomy with the patient's consent. The tissue was immersed in $4 \%$ paraformaldehyde in $0.1 \mathrm{M}$ phosphate buffer ( $\mathrm{pH} 7.4$ ) for 2 days. The fixed tissues were dehydrated through a graded series of ethanol and embedded in paraffin according to the conventional method. Paraffin sections of $4 \mu \mathrm{m}$ thickness were prepared and mounted on gelatin-coated glass slides. After pretreatment with normal goat serum (diluted $1: 20$ ), the dewaxed paraffin sections were incubated with anti-synthetic peptide antisera (diluted $1: 1,000-1: 4,000$ ) overnight at room temperature and then with biotinylated goat anti-rabbit IgG and streptoavidinperoxidase complex (Histofine kit, Nichirei, Tokyo, Japan). The antigen-antibody complex was visualized by incubation with $0.02 \% 3,3$ '-diaminobenzidine in $50 \mathrm{mM}$ Tris- $\mathrm{HCl}$ (pH7.6) containing $0.002 \%$ hydrogen peroxide.

Immunoblot. Two preparations of human native PSA were purchased from Biogenesis (Poole, England, 
UK) (Lot No. 22073104) and Cortex Biochem (Lot No. 01H27C), respectively. Seminal fluid collected from a healthy male volunteer was stored at $-30^{\circ} \mathrm{C}$ until use. The frozen material $(25 \mathrm{~mL})$ was thawed and centrifuged at $3,500 \mathrm{rpm}$ for $20 \mathrm{~min}$ at room temperature. The supernatant was again centrifuged at $15,000 \mathrm{rpm}$ for $30 \mathrm{~min}$ to offer clear seminal plasma.

Native human PSA or human seminal plasma was submitted to electrophoresis on NuPAGE 4-12\% Bis-Tris polyacrylamide gel (NOVEX, San Giego, CA, USA) in the presence of SDS (SDS-PAGE). The proteins on the gel were electrotransferred to PVDF membrane (Millipore, Bedford, MA, USA) and the membrane was treated with blocking solution included in Western Immunodetection System, Western Breeze (Invitrogen, Carlsbad, CA, USA), under vigorous shaking for $90 \mathrm{~min}$ at room temperature.

The membrane was rinsed with $\mathrm{H}_{2} \mathrm{O}(20 \mathrm{~mL})$ for $5 \mathrm{~min}$, incubated with properly diluted anti-synthetic peptide antiserum $(10 \mathrm{~mL})$ for $60 \mathrm{~min}$ and rinsed three times with washing solution (Western Breeze) $(20 \mathrm{~mL}$ each). The membrane was then incubated with alkaline phosphatase-conjugated goat anti-rabbit IgG antiserum (Western Breeze) $(10 \mathrm{~mL}$ ) for $60 \mathrm{~min}$. The membrane was rinsed three times with washing solution $(20 \mathrm{~mL}$ each) and incubated with chromogenic substrate solution (Western Breeze). Finally, the membrane was rinsed three times with $\mathrm{H}_{2} \mathrm{O}(20 \mathrm{~mL}$ each).

EIA. Goat anti-rabbit-IgG Fc (ICN) (diluted $1: 200$ with $0.02 \mathrm{M}$ sodium phosphate buffer, $\mathrm{pH} 8.0$ ) was added to wells of a microtiter plate (NUNC, Maxisorp) $(0.1 \mathrm{~mL} /$ well $)$ and the plate was kept for $18 \mathrm{~h}$ at room temperature. The solution in the wells were decantated and 25\% diluted BlockAce (Dainihon Pharmaceutical) was added $(0.3 \mathrm{~mL} /$ well $)$ and the plate was incubated for $48 \mathrm{~h}$ at $4^{\circ} \mathrm{C}$. The wells were washed three times with washing solution $(0.05 \%$ Tween 20 in saline) and assay buffer (Dulbecco's PBS(-) containing $0.1 \%$ bovine serum albumin) was added $(0.05 \mathrm{~mL} / \mathrm{well})$. To the wells, were added standard peptide or unknown sample $(0.025 \mathrm{~mL} /$ well $)$ and biotin-labeled antigen solution $(0.5 \mathrm{ng} / \mathrm{mL}$ in assay buffer) $(0.05 \mathrm{~mL} /$ well $)$. Properly diluted anti-synthetic peptide in assay buffer was then added to the wells $(0.1 \mathrm{~mL} / \mathrm{well})$ and the plate was kept for $18 \mathrm{~h}$ at $4{ }^{\circ} \mathrm{C}$. The wells were washed three times with washing solution, and HRP-conjugated streptavidine solution (Oncogene, Boston, MA, USA) diluted 1 : 5,000 with assay buffer containing $0.05 \%$ Tween 20 was added $(0.1 \mathrm{~mL} /$ well). The plate was kept for 1.5 $h$ at room temperature and the wells were washed four times with washing solution. To the wells, OPD solution $(1 \mathrm{mg} / \mathrm{mL}, 0.1 \mathrm{M}$ citrate-phosphate buffer containing $0.05 \%$ hydrogen peroxide) was added $(0.1 \mathrm{~mL} / \mathrm{w}$ lil) and the plate was kept for $0.5 \mathrm{~h}$ at room temperature, followed by addition of $2 \mathrm{~N}$ $\mathrm{H}_{2} \mathrm{SO}_{4}(0.1 \mathrm{~mL} /$ well $)$. Optical absorption of the solution in each well was measured at $492 \mathrm{~nm}$ by a microtiter plate reader Multiskan MS.

Gel chromatography. Seminal plasma $(0.3 \mathrm{~mL})$, human serum $(0.3 \mathrm{~mL})$ and native PSA preparation (Cortex Biochem) (diluted $1: 100)(1 \mathrm{~mL})$ were respectively subjected to gel chromatography on a Sephadex G-75 superfine (Pharmacia Biotech, Inc., Uppsala, Sweden $)$ column $(1.7 \times 100 \mathrm{~cm})$ using $0.01 \mathrm{M}$ phosphate buffered saline as eluent at a flow rate of $1.3 \mathrm{~mL} / \mathrm{min}$. Each fraction $(2 \mathrm{~mL})$ was measured for PSA immunoreactivity (PSA-IR) by the EIA described above with anti-PSA (53-92) antiserum RY756, synthetic PSA (53-92) and biotinylGly-Gly-PSA (53-92).

Clinical Samples. Fourteen serum samples were collected from 11 patients (mean age : 71.5 \pm 7.7 years old) treated in our hospital with their consent, and stored at $-30^{\circ} \mathrm{C}$ until use. Five of the 11 patients have been diagnosed as benign prostatic hyperplasia and the residual 6 as prostate cancer. PSA levels of the 14 samples were measured by the current EIA with anti-PSA (53-92) antisenum RY756, synthetic PSA (42-92) and biotinyl-Gly-Gly-PSA (42-92) and by Immulyze fully automated random access immunoassay analyzer (Nippon DPC Corp., Chiba, Japan) (14).

\section{RESULS}

Anti-Synthetic Peptide Antisera

Antisera raised against PSA-related synthetic peptide, PSA (42-92), (53-92), (50-70), (76-92), (174$184)$ and $(199-210)$ all showed appreciable binding ability to the respective immunogen peptides at dilution $1: 1,000^{-1}: 10,000$ (Table 1). On the other hand, antisera that had practically applicable binding activity to native PSA were limited to those indicated in Fig. 2, i.e. anti-PSA (42-92) antisera RY1187, RY1188 and RY1189, anti-PSA (53-92) antisera RY756 and RY757 and anti-PSA $(50-70)$ antisera RY610, RY611, RY612 and RY613. 


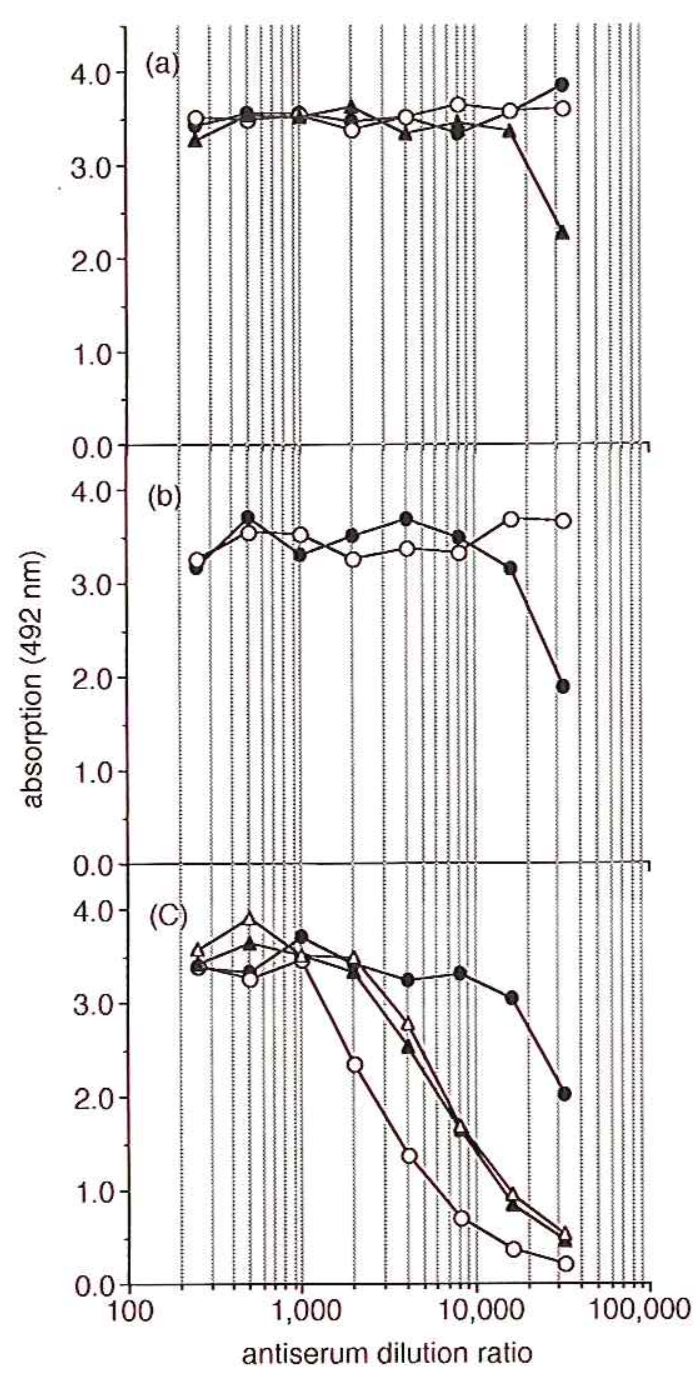

Fig. 2 Native PSA binding assay for anti-synthetic peptide antisera. (a) anti-PSA (42-92) antisera RY1187 (o), RY1188 (O) and RY1189 (A). (b) anti-PSA (53-92) antisera RY756 (o) and RY757 (O). (c) anti-PSA (50-70) antisera RY610 (0), RY611 (O), RY612 (A) and RY613 $(\triangle)$.

\section{Immunohistochemistry}

Fig. 3 shows immunostaining of serial sections from human prostate tissue with anti-PSA (53-92) antisera RY756 and RY757. PSA-IR was localized only in the epithelial cells lining the acini. Besides the two antisera, anti-PSA (50-70) antiserum RY610 (diluted $1: 3,000-1: 4,000)$ gave identical result of staining, and anti-PSA $(50-70)$ antisera RY612 $(1: 1,000)$ and RY613 $(1: 1,000)$ and anti-PSA (199-210) antisera RY614 $(1: 4,000)$ and RY622 $(1: 1,000)$ detected PSA-IR in human prostate but
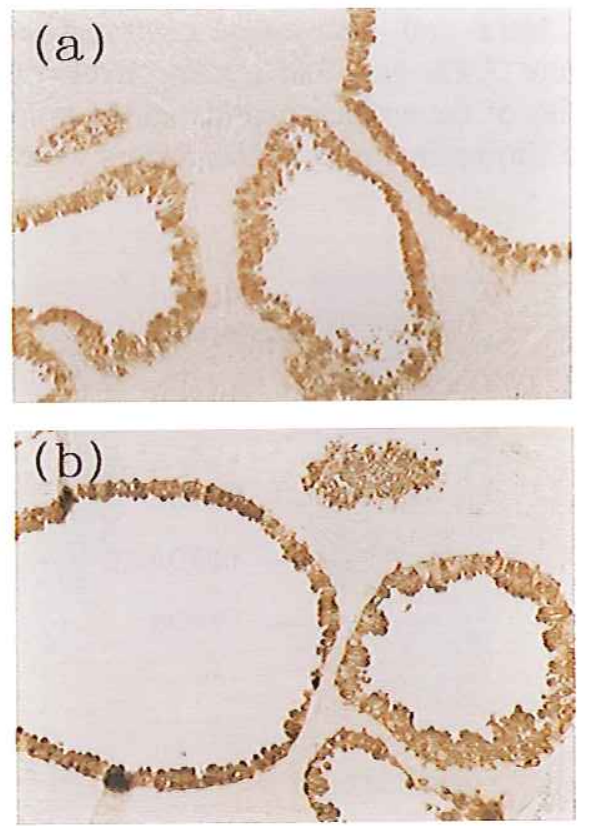

Fig. 3 Immunostaining of human prostate with antiPSA (53-92) antisera (a) RY756 (1:4,000) and (b) RY757 $(1: 4,000)$.

the staining results were not as good as the above cases. None of anti-PSA (76-92) and anti-PSA (174184) antisera yielded significant positive staining for PSA-IR in the tissue. Anti-PSA (42-92) antisera were not examinated.

\section{Immunoblot}

Fig. 4 shows immunoblot of two preparations of native PSA (lanes 1 and 2) and PSA-IR in human seminal plasma (lane 3) with anti-PSA-(53-92) antiserum RY756. The antiserum was crossreacted with both of the PSA preparations indicating a band at a position corresponding to $29 \mathrm{kDa}$. Seminal plasma showed main three bands corresponding to 29,77 and $135 \mathrm{kDa}$, respectively.

EIA

Anti-PSA (53-92) antiserum RY756 was proved to be one of the best among those obtained in the current study by immunohistochemistry, immunoblot and sensitivity of inhibition activity of PSA (42-92) against antiserum-binding of labeled PSA (42-92). Accordingly antiserum RY756 was used at 1:5,000 initial dilution for development of PSA specific EIA. A typical standard curve is shown in Fig. 5, in which PSA (42-92) was used as standard antigen and biotinyl-Gly-Gly-PSA (42-92) as labeled antigen. The minimum dose of detection was 100 
$\mathrm{pg} / \mathrm{mL}$. Intra- and inter-assay coefficients of variance were $7.4 \%$ and $9.6 \%$, respectively. Analitical recoveries of the antigen peptide added to human serum are shown in Table 2 . The results were satisfac-

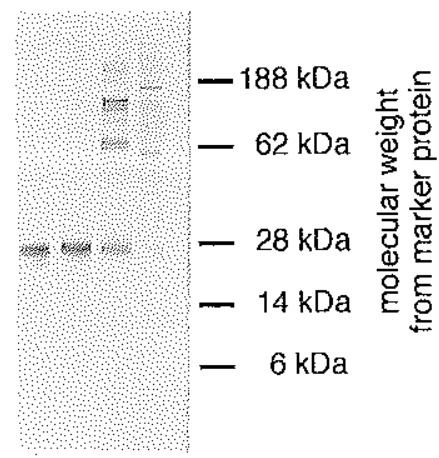

1234

lane number

Fig. 4 Immunoblot of native PSA preparations and seminal plasma with anti-PSA (53-92) antiserum RY756. Lane 1: native PSA from Biogenesis. Lane 2: native PSA from Cortex Biochem. Lane 3: seminal plasma.

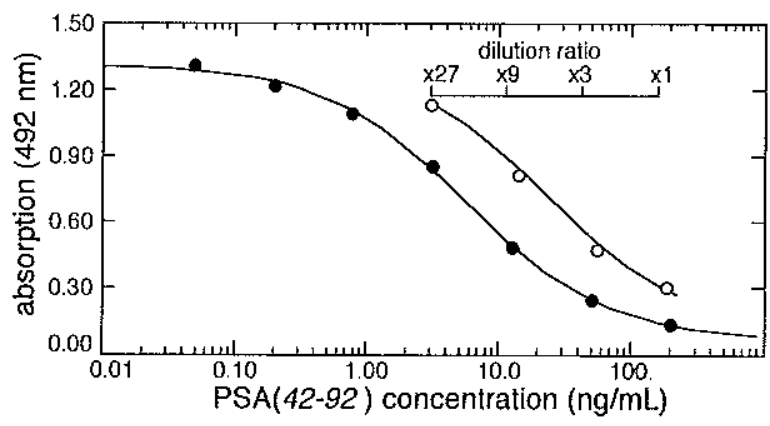

Fig. 5 A typical standard curve (๑) of PSA EIA with anti-PSA (53-92) antiserum RY756, synthetic PSA (4292) as standard antigen and biotinyl-Gly-Gly-PSA (4292) as labeled antigen and a dilution curve $(O)$ of human seminal plasma. tory. The dilution curve of human seminal plasma in the current assay system was parallel to the standard curve (Fig. 5).

\section{Gel chromatography}

Fig. 6 indicates gel chromatographic profiles of human seminal plasma (a), human serum (b) and native PSA preparation (c). All the specimen respectively showed a single peak of PSA-IR at the position where native PSA preparation was eluted.

\section{Clinical Data}

Serum levels of PSA-IR from 11 patients were measured with two PSA assay systems: one the current EIA and the other a commercial solid phase RIA for free PSA. As shown in Fig. 7, there was observed

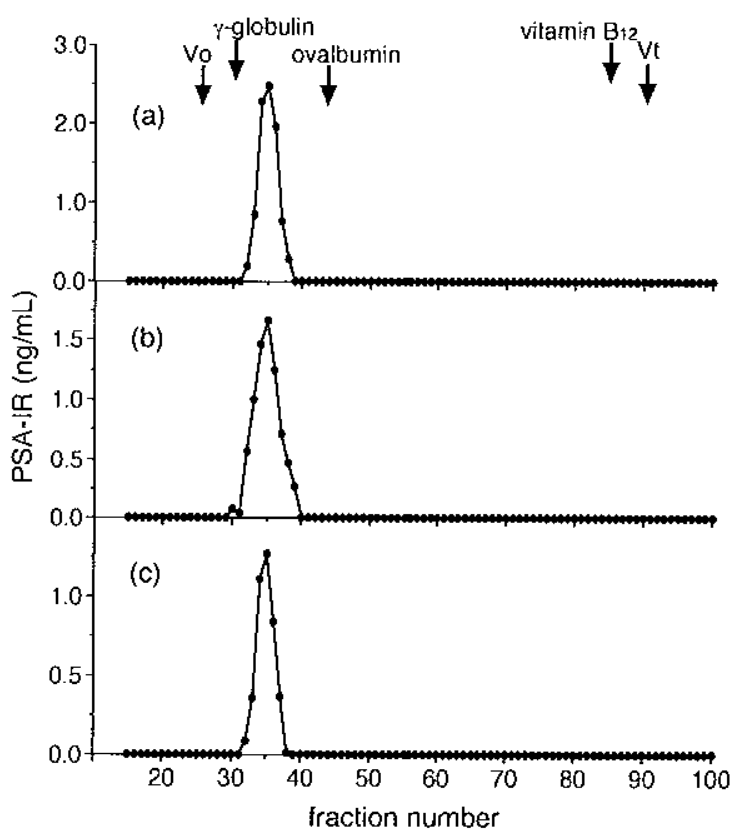

Fig. 6 Gel chromatographic profiles of PSA-IR in (a) human seminal plasma, (b) human serum and (c) native PSA preparation (Cortex Biochem).

Table 2 Analytical recovery of PSA (42-92) added in human serum in the current EIA.

\begin{tabular}{cccc}
\hline $\begin{array}{c}\text { PSA(42-92) } \\
\text { added (ng/m) }\end{array}$ & $\begin{array}{c}\text { observed } \\
(\mathrm{ng} / \mathrm{ml})\end{array}$ & $\begin{array}{c}\text { expected } \\
(\mathrm{ng} / \mathrm{ml})\end{array}$ & $\begin{array}{c}\text { recovery } \\
(\%)\end{array}$ \\
\hline 0 & 0.32 & & \\
0.4 & 0.86 & 0.72 & 119.44 \\
2 & 2.88 & 2.32 & 124.14 \\
10 & 9.81 & 10.32 & 95.06 \\
\hline
\end{tabular}

EIA with anti-PSA (53-92) antiserum RY756, synthetic PSA (42-92) and biotinyl-Gly-Gly-PSA (42-92) 


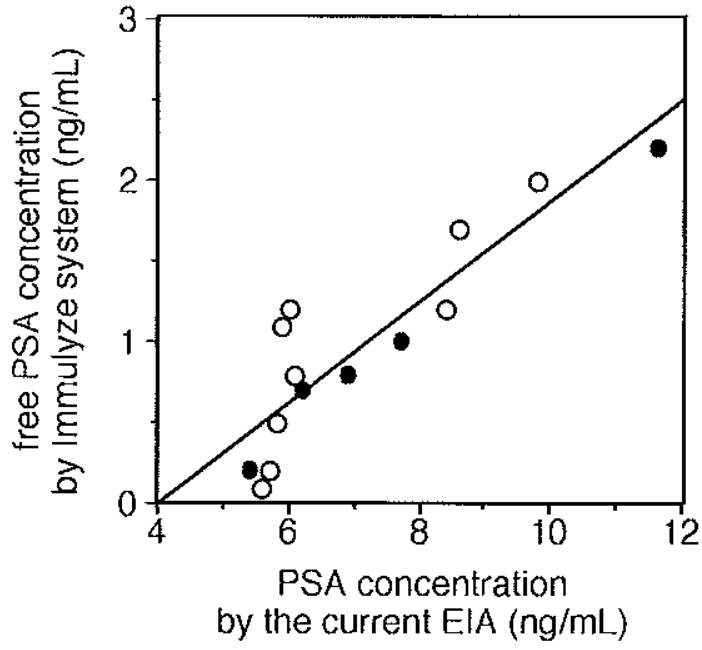

Fig. 7 Relation between PSA-IR in patients with prostate cancer $(O)$ and benign prostatic hyperplasia (๑) measured by the current EIA and a commercial assay kit Immulize.

significant correlation between the serum PSA-IR levels measured by the two assay systems $(\mathrm{r}=0.891$, $\mathrm{p}=0.0018, \mathrm{n}=14$ ), although the levels measured by the current assay system was higher than those by a commercial free PSA assay.

\section{DISCUSSION}

The immunochemical measurement of serum PSA is now most frequently used diagnostic approach to prostate cancer. In early studies after the first trial of PSA testing in 1986 (4), however, there have been claimed several limitations, especially in immunological specificity of the method for clinical use (18). This in turn prompted the molecular biological research of the protein and afforded a better understanding of the molecular features of PSA together with those of closely related proteases (16). The diagnostic quantification of PSA in blood is performed by immunoassay using mono- / polyclonal antibodies against native or recombinant PSA. The specificity of an antibody elicited against the whole molecule of PSA is not predictable and it is not feasible to obtain invariably an antibody having a certain specificity. We have now abundant information about the structural characteristics $(16,18)$ which enables us to select the region most favorable as epitope of an antibody used for PSA immunoassay. Based on our previously accumulated achievements $(1,22,23,24)$, we have thus decided to use purposely-designed synthetic peptides corresponding to partial sequences of PSA as antigens in order to produce strictly region-specific anti-PSA antibodies.

On the selection of regions as targets for synthesis of antigen peptides, the first issue to be considered was structural similarity among PSA, hK1 and hK2 (18). The $\mathrm{hK} 1$ is expressed in nonprostatic tissues having $62 \%$ amino acid sequence identity with PSA, and $\mathrm{hK} 2$ is glandular kallikrein with $79 \%$ homology. The human prostate is known to secrete low amounts of a kallikrein detected by antibodies directed against hKl (8). However, the specificity of the antibodies was not enough confirmed to prove the existence of hKl itself in the prostate (8). The hK2 gene was reported to be expressed in the prostatic epithelial cells as the PSA gene (10), and the expression of hK2 mRNA was about $10^{-} 50 \%$ that of PSA mRNA (18). On the contrary, the protein appeared to be present at a very low concentration in the prostate cytosol and seminal plasma (8). In fact, the $\mathrm{hK} 2$ concentration found in seminal plasma was $0.1-1 \%$ of the PSA concentration and lower than $2 \%$ in serum (5).

First, we selected the (42-92) sequence of PSA as a target of antigen peptide synthesis. The sequence shows $64.7 \%$ homology with the corresponding sequence of $\mathrm{hK} 1$ and $52.9 \%$ with $\mathrm{hK} 2$, which is much less as compared with the hK2 molecules. Besides, the recognition site of free PSA by some monoclonal antibodies was demonstrated to exist within the (69-93) sequence (16), and the (80-9l) region is described to be mostly solvent exposed (16). The lower sequence homology with hK1 and hK2 is also observed in the $(143-186)$ sequence of PSA, but it contains four of the total ten Cys residues in PSA, which is supposed to make it difficult to keep purity of synthetic peptides during immunochemical experiment. Although the carboxy terminal region of PSA shows rather higher homology with hK2, we synthesized PSA (199-210)-R as antigen according to the favorable result of the hydropathy and secondary structure analysis which have been successfully used for the same purpose in our laboratory. PSA $\left(76^{-92)}\right.$ and (174-184) peptides were synthesiged for the same reason.

Immunization of the six kinds of synthetic peptides, free or conjugated with KLH, afforded seventeen antisera (Table 1), among which nine anti-PSA (42-92), anti-PSA (53-92) and anti-PSA $\left(50^{-} 70\right)$ antisera exhibited reliably high titers in binding to native PSA (Fig. 2). However, for the purpose of the current study to develop immunoassay system for PSA, the antigen-binding affinities of the anti-PSA $(42-92)$ antisera group were found to be excessively 
high. On the other hand, the titers of anti-PSA $\left(50^{-}\right.$ 70 ) antisera were rather lower. It was already demonstrated that PSA was produced in males by the columnar epithelial cells of the prostate $(10,17)$. Of the current antisera produced, anti-PSA (53-92) antisera, RY756 and RY757, reproduced most clearly the typical pattern of immunostaining in the prostate (Fig. 3), confirming the high specificity for PSA of the two antisera. The other antisera produced also demonstrated the same pattern of staining, but the results were not as good as those of the above two. Based on these data, we chose the two anti-PSA (5392) antisera to develop a novel immunoassay system characterized by the use of synthetic peptide antigens and anti-synthetic peptide antisera.

Immunoblot analysis of two native PSA preparations with antiserum RY756 revealed a single band corresponding to a molecular mass of $29 \mathrm{kDa}$ (Fig. 4). This again confirmed the specificity of the antiserum. It is known that $20-30 \%$ of PSA preparation are clipped at three sites, between $85-86,145-146$ and $182-183$, but the clipped protein remains connected by the internal disulfide bonds (21). Intact and clipped PSA molecules, therefore, comigrate in SDS-PAGE under non-reducing condition as presently used. No information is available for the presence or absence of clipped PSA in the commercial native PSA preparations used. In addition, specificity of antisera RY756 and RY757 was not directly confirmed for native PSA clipped between residues 85-86 (18). However, we observed that the antisera raised against PSA (76-92) were all less efficient in binding to native PSA as compared with the antisera against amino terminal extended peptides, i.e. PSA $(42-92),(53-92)$ and $(50-70)$. The antisera against these amino terminal extended peptides are supposed to recognize more remote region from the clipping site than the case of the antisera against PSA (76-92). This may imply that the antisera RY756 and RY757 recognize PSA clipped between residues $85-86$ as well as native form of PSA. In this context, the single bands observed with native PSA preparations are possible to include clipped PSA, if any. On the other hand, immunoblot of seminal plasma with antiserum RY756 showed three bands, one of which corresponded to native PSA. It was reported that $20 \%$ to $30 \%$ of PSA preparations from seminal fluid were in clipped form (18). The band may represent, at least partially, clipped PSA. The other two bands corresponded to higher molecular masses (77 and $135 \mathrm{kDa})$. It was described that PSA is capable of forming covalently linked complexes with certain serine protease inhibitors in se- rum and that these complexes are not dissociated by harsh treatment (3). It is well known that some of anti-PSA antibodies can recognize PSA in complexed forms with certain protease inhibitors. Accordingly, the band corresponding to $77 \mathrm{kDa}$ is supposed to represent complexed form of PSA with protein $\mathrm{C}$ inhibitor (7) which had been immunodetected in seminal plasma at high concentration $(6$, 13). This in turn supports that antiserum RY756 can recognize PSA in complexed form as well as that in free form. The band of the highest molecular mass may represent PSA complexed with unidentified protein with higher molecular mass. Also, the possibility of polymerization of PSA during storage of the sample may not be excluded. This higher molecular mass PSA-IR remains to be identified. There is observed no band corresponding to the molecular mass of hK2 (22 kDa) (15).

The successful production of region-specific antiPSA antisera using synthetic peptides enabled us to develop a new type of EIA system for PSA (Fig. 5). The assay system utilized only synthetic peptides as standard antigen and labeled antigen. It was proved to recognize seminal PSA immunologically as standard synthetic peptide by dilution test (Fig. 5) and gel chromatography (Fig. 6). Together with the data of stability, sensitivity and analytical recovery tests of the assay system, all data supported the usefulness of the current assay system for practical purpose. As a preliminary trial, we applied the system to measure serum PSA in patients with prostate cancer and benign prostatic hyperplasia and the results were compared with those measured by a commercial free PSA-specific EIA kit (Fig. 7). The results of both assays showed an apparent correlation. However, since the current assay system recognizes both free and complexed forms of PSA, the relationship must carefully be analyzed with a larger number of samples.

PSA measurement is acquiring greater importance in the clinical management of prostate cancer. However, there still exist some problems to be solved. This is mainly attributable to the diverse forms of PSA in blood, and, therefore, the specificity of PSA assay system (the epitope of antibody) used in regarded as the most important factor that should be assured. It is, however, only by chance to obtain an antibody against a certain protein having the desired epitope and it is most laborious work to analyze epitopes of antibodies raised against a certain protein. The current study enabled us to raise PSA antibodies having epitopes in strictly limited regions desired. This methodology will provide a useful and 
efficient tool to analyze more precisely the relation between PSA molecular forms in blood and specificities of antibodies recognizing them, which will make clinical PSA assay more reliably standardized. Production of PSA antisera specific to other regions of PSA molecule is being attempted by this method.

\section{REFERENCES}

1. Arakawa Y., Takao E., Hirotani Y., Kato I., Jun L., Yanaihara N., Yanaihara C., Iwanaga T. and Kurokawa N. (2002) Immunochemical characterization and measurement of neuronal type nitric oxide synthase in human neuroblastoma NB-OK-1 cell using novel anti-synthetic peptide antibody and specific immunoassay system. Regul. Pept. 106, 115-123.

2. Brady J. M., Wines D. R. and MacDonald R. J. (1989) Expression of Two Kallikrein Gene Family Members in the Rat Prostate. Biochemistry 28, 5203-5210.

3. Christensson A., Björk T., Nilsson O., Dahlén U., Matikainen M. T., Cockett A. T. K., Abrahamsson P. A. and Lilja H. (1988) Serum prostate specific antigen complexed antichymotrypsin as an indicator of prostate cancer. J. Urol. 150, 100-105.

4. Christensson A., Laurell C. B. and Lilja H. (1990) Enzymatic activity of prostate-specific antigen and its reactions with extracellular serine proteinase inhibitors. Eur: J. Biochem. 194, 755-763.

5. Deperthes D., Chapdelaine P., Tremblay R. R., Brunet C., Berton J., Hébert J., Lazure C. and Dube J. Y. (1995) Isolation of prostatic kallikrein hK2, also known as hGK-1, in human seminal plasma. Biochem. Biophys. Acta 1245, 311-316.

6. Espana F., Gilabert J., Estelles A., Romeu A., Aznar J. and Cabo A. (1991) Functionally active protein C inhibitor/plasminogen activator inhibitor-3 (PCI/PAI-3) is secreted in seminal vesicles, occurs at high concentrations in human seminal plasma and complexes with prostate-specific antigen. Thromb. Res. 64, 309-20.

7. Espana F., Sanchez-Cuenca J., Vera C. D., Estelles A. and Gilabert J. (1993) A quantitative ELISA for the measurement of complexes of prostate-specific antigen with protein $\mathrm{C}$ inhibitor when using a purified standard. J. Lab. Clin. Med. $122,711-719$.

8. Fink E., Schill W. B., Fiedler F., Kassnigg F., Geiger R. and Shimamoto K. (1985) Tissue kallikrein of human seminal plasma is secreted by the prostate gland. Biol. Chem. HoppeSeyler 366, 91-924.

9. Graves H. C. B. (1993) Standardization of immunoassays for prostate-specific antigen- a problem of prostate-specific antigen complexation or a problem of assay design? Cancer 72, 3141-3144.

10. Henttu P. and Vihko P. (1994) Prostate-specific antigen and human glandular kallikrein: two kallikreins of the human prostate. Ann. Med. 26, 157-164.

11. Kurokawa N., Hirotani Y., Arakawa Y., Iguchi K., Urabe N., Yanaihara N., Abe K. and Yanaihara C. (1990) Increased production of $\mathrm{c}$-myc and $\mathrm{c}$-fos related proteins during late stage of regenerative process in rat liver after partial hepatectomy. Biomed. Res. 11, 165-172.
12. Kurokawa N., Hirotani Y., Takashima N., Sawada M., Iguchi K., Yanaihara N., Arakawa Y. and Yanaihara C. (1995) RB gene product levels measured by a specific radioimmunoassay decrease in regenerating rat liver after partial hepatectomy. Biomed. Res. 16, 69-72.

13. Laurell M., Christensson A., Abrahamsson P. A., Stenflo J. and Lilja H. (1992) Protein C inhibitor in human body fluid. J. Clin. Invest. 89, 1094-1101.

14. Maeda H., Arai Y., Ishitoya S., Okubo K., Aoki Y., Okada T. and Maekawa $S$ (1998) Free to total prostate specific antigen ratio in clinical staging of prostate cancer. Acta Urol. Jpn. 44, 307-311.

15. McCormack R. T., Wang T. J., Rittenhouse H. G., Wolfert R. L., Finlay J. A., Lilja H., Sokoloff R. L. and Oesterling J. E. (1995) Molecular forms of prostate-specific antigen and the human kallikrein gene family: A new era. Urology 45, $729-$ 744.

16. Piironen T., Villoutreix B. O., Bécker C., Hollingsworth K., Vihinen M., Bridon D., Qiu X., Rapp J., Dowell B., Lovgren T., Pettersson K. and Lilja H. (1998) Determination and analysis of antigen epitopes of prostate specific antigen (PSA) and human glandular kallikrein 2 (hK2) using synthetic peptides and computer modeling. Protein Science 7, 259-269.

17. Sinha A. A., Wilson M. J. and Gleason D. F. (1987) Immunoelectron microscopic localization of prostate-specific antigen in human prostate by the protein A-gold complex. Cancer 60, 1288-1293.

18. Stamey T. A., Yang N., Hay A. R., McNeal J. E., Freiha F. S. and Redwine E. (1987) Prostate-specific antigen as a serum marker for adenocarcinoma of the prostate. N. Engl. J. Med. 317, 909-916.

19. Stenman U. H., Leinonen J., Alfthan H., Ranniko S., Tuhkanen K. and Alfthan O. (1991) A complex between prostate specific antigen and $\alpha 1$-antichymotrypsin is the major form of prostate-specific antigen in serum of patients with prostatic cancer: assay of the complex improves clinical sensitivity for cancer. Cancer Res. 51, 222-226.

20. Wang M. C., Valenzuela L. A., Murphy G. P. and Chu T. M. (1979) Purification of human prostate specific antigen. Invest. Urol. 17, 159-163.

21. Watt K. W., Lee P-J., M'Timkulu T., Chan W. P. and Loor R. (1986) Human prostate-specific antigen: structural and functional similarity with serine proteases. Proc. Natl. Acad. Sci. USA 83, 3166-3170.

22. Yanaihara C., Kadowaki M., Hoshino M., Kishida S., Suzuki T. and Yanaihara N. (1987) Production of region-specific antisera to human prorenin and rennin using synthetic peptides. Biomed. Res. 8, 95-101.

23. Yanaihara H., Hata M., Nishikawa Y., Hoshino M., Yanaihara N. and Murai M. (1999) Application of region-specific immunoassay for human chromogranin A: Substantial clue for detection and measurement of chromogranin $A$ in human plasma. Regul. Pept. 80, 83-90.

24. Yanaihara N., Yanaihara C., Hoshino M., Mochizuki T. and Iguchi K. (1988) Immunochemical and biochemical properties of purposely designed synthetic peptides. Ann. N.Y. Acad. Sci. 527, 29-43. 